\section{ORIGINAL RESEARCH}

\author{
Y. Ding \\ D. Dai \\ R. Kadirvel \\ D.A. Lewis \\ D.F. Kallmes
}

\title{
Creation of Large Elastase-Induced Aneurysms: Presurgical Arterial Remodeling Using Arteriovenous Fistulas
}

\begin{abstract}
BACKGROUND AND PURPOSE: The size of elastase-induced aneurysms created in the usual way is relatively small. Our aim was to determine whether creation of a carotid-jugular AVF to induce remodeling of the RCCA results in larger elastase-induced aneurysms in rabbits.
\end{abstract}

MATERIALS AND METHODS: RCCA right-jugular AVFs were created in 6 New Zealand white rabbits (group 1), followed by elastase-induced aneurysm creation 4 weeks later. Follow-up DSA was performed to assess AVF patency and aneurysm sizes. Six other elastase-induced aneurysms created in the usual way were used as controls (group 2). The diameters of the RCCA and LCCA in group 1 and aneurysm sizes in both groups were measured from DSA images and compared by using the Student $t$ test.

RESULTS: The patency of AVFs in group 1 was confirmed in all $6(100 \%)$ cases. The mean RCCA diameter in group 1 was larger than that in the contralateral LCCA $(3.6 \pm 0.7 \mathrm{~mm}$ versus $2.0 \pm 0.1 \mathrm{~mm}$, range, $1.8-2.2 \mathrm{~mm}, P<.01)$. The mean aneurysm neck diameter, width, and height for group 1 was larger than those of group $2(4.6 \pm 0.9 \mathrm{~mm}$ versus $3.5 \pm 0.7 \mathrm{~mm}, P<.05 ; 4.7 \pm 1.1 \mathrm{~mm}$ versus $3.4 \pm$ $0.5 \mathrm{~mm}, P<.05 ; 13.8 \pm 3.2 \mathrm{~mm}$ versus $8.1 \pm 1.3 \mathrm{~mm}, P<.05$, respectively). Aneurysm volume for group 1 was significantly larger than that of group $2\left(273 \pm 172 \mathrm{~mm}^{3}\right.$ versus $\left.77 \pm 32 \mathrm{~mm}^{3}, P<.05\right)$.

CONCLUSIONS: Carotid-jugular AVFs result in RCCA remodeling that yields relatively larger elastaseinduced aneurysms.

ABBREVIATIONS: AVF = arteriovenous fistula; DSA = digital subtraction angiography; IADSA = intra-arterial DSA; IVDSA = intravenous DSA; LCCA = left common carotid artery; RCCA = right common carotid artery; REJV = right external jugular vein

$\mathbf{T}$ he elastase-induced aneurysm model in rabbits has been widely used in basic and preclinical research, especially in the evaluation of neuroendovascular devices. ${ }^{1-14}$ The advantage of this model is that it closely simulates the morphology and hemodynamics of human intracranial aneurysms. ${ }^{1,10}$ However, unlike surgically created aneurysm models, the maximum size of the rabbit elastase-induced-model aneurysm is relatively small. ${ }^{15-17}$ As such, the model does not show high rates of recurrence after coil embolization, which would be a desirable trait for testing new endovascular devices. ${ }^{11,18,19}$

Various modifications have been made to the elastase aneurysm model to alter its size and morphology, including such aspects as the location of the carotid artery ligation. ${ }^{20-25} \mathrm{Al}-$ though not previously applied in aneurysm research, surgically created AVFs have been used to stimulate arterial remodeling in animal models. ${ }^{26}$ Such remodeling acts in response to elevated arterial flow, with well-defined molecular signaling pathways $^{27,28}$ and resultant chronic enlargement of the arterial diameter.

We hypothesized that the size of elastase-induced aneu-

Received January 31, 2010; accepted after revision May 10.

From the Neuroradiology Research Laboratory, Department of Radiology, Mayo Clinic, Rochester, Minnesota.

This work was supported by the National Institutes of Health grant R01 NS46246.

Please address correspondence to David F. Kallmes, MD, Mayo Clinic, 200 First St SW, Rochester, MN 55905; e-mail: kallmes.david@mayo.edu

Indicates open access to non-subscribers at www.ajnr.org

DOI 10.3174/ajnr.A2205 rysms in rabbits could be increased if such aneurysms were created in the setting of a chronic AVF, which would act to remodel and enlarge the carotid artery before elastase injury and aneurysm creation. In the current study, we report our preliminary experience with elastase aneurysm creation following AVF creation to determine whether resultant aneurysms are larger in the setting of successful patent AVFs compared with aneurysms created in the usual way. ${ }^{1}$

\section{Materials and Methods}

\section{Creation of Carotid-Jugular AVF}

Following approval from our Institutional Animal Care and Use Committee, carotid-jugular AVFs were created in 6 New Zealand white rabbits (group 1). The RCCA and REJV were exposed and dissected. An arteriotomy of the RCCA was performed, and aneurysm clips were used to temporally occlude the proximal and distal side of the arteriotomy. The REJV was cut into 2 segments; the proximal side of the REJV was used for end-to-side anastomosis to the RCCA by using a 7-0 Prolene suture (Ethicon, Cincinnati, Ohio). The distal RCCA was permanently ligated by using $4-0$ silk. An end-to-side anastomosis of the REJV and RCCA was performed, and the AVF was created. Animals were allowed to recover and were maintained for at least 4 weeks before aneurysm creation.

\section{Aneurysm Creation}

In the same subjects detailed above, elastase-induced saccular aneurysms were created. IVDSA was performed before aneurysm creation to evaluate the patency of the AVF and to determine the diameters of the carotid arteries by using procedures described previously by our 


\begin{tabular}{lcccc}
\hline \multicolumn{5}{l}{ Sizes of aneurysms created after AVF establishment } \\
\hline $\begin{array}{l}\text { Rabbit } \\
\text { No. }\end{array}$ & $\begin{array}{c}\text { Time between } \\
\text { 2 Procedures } \\
\text { (weeks) }\end{array}$ & $\begin{array}{c}\text { Neck } \\
(\mathrm{mm})\end{array}$ & $\begin{array}{c}\text { Width } \\
(\mathrm{mm})\end{array}$ & $\begin{array}{c}\text { Height } \\
(\mathrm{mm})\end{array}$ \\
\hline 1 & 4 & 3.5 & 4.2 & 11.2 \\
2 & 4 & 5.4 & 5.4 & 16.1 \\
3 & 4 & 4.1 & 3.8 & 14.8 \\
4 & 4 & 5.5 & 6.4 & 16.8 \\
5 & 4 & 4 & 3.4 & 8.6 \\
6 & 5 & 5.3 & 5.2 & 15 \\
\hline
\end{tabular}

group. ${ }^{29}$ Briefly, $7 \mathrm{~mL}$ of iodinated contrast material (iohexol, Omnipaque 300; GE Healthcare, Milwaukee, Wisconsin) was injected into the left ear-vein catheter at approximately $2 \mathrm{~mL} / \mathrm{s}$ during DSA; the $\mathrm{x}$-ray exposure rate was 2 frames per second. The diameters of the RCCA and control LCCA 4 weeks after AVF creation were determined in comparison with external sizing devices. Following IVDSA, aneurysms were created.

Detailed procedures for aneurysm creation have been described previously. ${ }^{1}$ Briefly, anesthesia was induced with an intramuscular injection of ketamine, xylazine, and acepromazine (75, 5, and $1 \mathrm{mg} /$ $\mathrm{kg}$, respectively). Using a sterile technique, we re-exposed and isolated the RCCA. The AVF was disconnected at the surgical anastomotic site. A 1- to 2-mm bevelled arteriotomy was made, and a $5 \mathrm{~F}$ vascular sheath (Cordis Endovascular, Miami Lakes, Florida) was advanced retrograde in the RCCA to a point approximately $3 \mathrm{~cm}$ cephalad to the origin of RCCA. A roadmap image (Advantx, GE Healthcare) was obtained by injection of contrast through the sheath retrograde in the RCCA, to identify the junction between the RCCA and the subclavian and brachiocephalic arteries. A 3F Fogarty balloon (Baxter Healthcare, Irvine, California) was advanced through the sheath to the level of the origin of the RCCA with fluoroscopic guidance and was inflated with iodinated contrast material.

Porcine elastase $(5.23 \mu \mathrm{m} / \mathrm{mgP}, 40.1 \mathrm{mgP} / \mathrm{mL}$, approximately 200 U/mL; Worthington Biochemical, Lakewood, New Jersey) was incubated within the lumen of the common carotid artery above the inflated balloon for 20 minutes; then, the catheter, balloon, and sheath were removed, and the RCCA was ligated below the sheath entry site. Six aneurysms (group 2) were randomly selected from 22 elastaseinduced aneurysms we created before in the usual manner ${ }^{1}$ without a fistula. Ligation positions of the RCCA in groups 1 and 2 were similar, approximately $3 \mathrm{~cm}$ cephalad to the origin of the RCCA. Our previous experience indicated that a ligation position of the RCCA of $<1 \mathrm{~cm}$ will impact the aneurysm height and volume. ${ }^{25} \mathrm{~A}$ ligation position of
$>3 \mathrm{~cm}$ will not impact aneurysm height and volume by itself, so the aneurysm height in those 2 groups is comparable.

\section{Imaging Follow-Up}

Three weeks after aneurysm creation, the width, height, and neck diameters of the aneurysm cavities were determined with IVDSA by using the same external sizing device as a reference. IADSA was performed in group 2 three weeks after aneurysm creation. Details of the IADSA procedure were demonstrated previously. ${ }^{29}$ The aneurysm volume was calculated as

$$
\text { Volume } \left.=3.14(\text { width } / 2)^{2} \text { (height }\right) \text {. }
$$

The diameter of the RCCA at initial follow-up, immediately before aneurysm-creation surgery, was compared with that of the LCCA in group 1; and the aneurysm dimensions 3 weeks following aneurysm creation were compared between groups by using the Student $t$ test.

\section{Results}

Six (100\%) AVFs remained patent in group 1. The times between the 2 procedures (AVF and aneurysm creation) and aneurysm sizes are shown in the Table. The mean RCCA diameter $(3.6 \pm 0.7 \mathrm{~mm}$, from 2.6 to $4.2 \mathrm{~mm}$ ) was larger than that of the contralateral LCCA $(2.0 \pm 0.1 \mathrm{~mm}$, from 1.8 to 2.2 $\mathrm{mm})$ at initial follow-up in group $1(P<.01)$ (Fig $1 A)$.

The mean aneurysm neck diameter for group 1 ( $4.6 \pm 0.9$ $\mathrm{mm}$, from 3.5 to $5.5 \mathrm{~mm}$ ) was larger than that of group 2 $(3.5 \pm 0.7 \mathrm{~mm}$, from 2.5 to $4.3 \mathrm{~mm})(P<.05)$. Differences in aneurysm width between group $1(4.7 \pm 1.1 \mathrm{~mm}$, from 3.4 to $6.4 \mathrm{~mm})$ and group $2(3.4 \pm 0.5 \mathrm{~mm}$, from 2.9 to $4.3 \mathrm{~mm})$ were also significant $(P<.05)$. Mean aneurysm height was greater in group 1 (13.8 $\pm 3.2 \mathrm{~mm}$, from 8.6 to $16.8 \mathrm{~mm}$ ) compared with group $2(8.1 \pm 1.3 \mathrm{~mm}$, from 6.4 to $9.5 \mathrm{~mm})(P<.05)$. Aneurysm volume in group $1\left(273 \pm 172 \mathrm{~mm}^{3}\right.$, from 77 to 369 $\left.\mathrm{mm}^{3}\right)$ was significantly larger than that of group $2(77 \pm 32$ $\mathrm{mm}^{3}$, from 44 to $\left.138 \mathrm{~mm}^{3}\right)(P<.05)$ (Fig $\left.1 B,-C\right)$.

\section{Discussion}

The elastase aneurysm is widely applied for both basic research and testing of neuroendovascular devices. ${ }^{30-34}$ Unlike vein pouch models, in which large-diameter veins can be harvested to create large aneurysms, the ultimate size of the elastaseinduced-model aneurysms likely is limited by the initial size of the RCCA. ${ }^{1,35-37}$ In an attempt to increase the size of elastase-
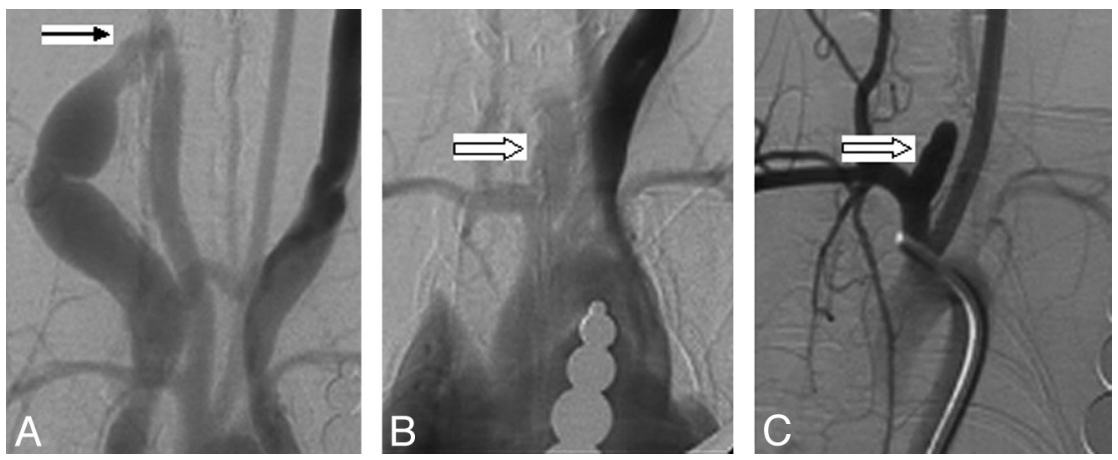

Fig 1. $A$, Anteroposterior IVDSA image 4 weeks following AVF creation but immediately before aneurysm-creation surgery. Both the RCCA and the REJV are shown, indicating a patent AVF (arrow) and a larger RCCA compared with the LCCA. B, IVDSA image 3 weeks following aneurysm-creation surgery in the same animal as in $A$, demonstrating a relatively large aneurysm cavity (block arrow). Aneurysm dimensions were $6.4 \mathrm{~mm}$ in width and $16.8 \mathrm{~mm}$ in height with a neck measuring $5.5 \mathrm{~mm}$. C, IADSA image 3 weeks following aneurysm creation in group 2, demonstrating a small aneurysm (block arrow). Aneurysm sizes of the neck, width, and height were 3.4, 3.6, and 8.4 mm, respectively. 
induced aneurysms, we induced arterial remodeling by using chronic AVF before aneurysm-creation surgery. We have demonstrated positive remodeling in patent AVF cases, indicating, as expected, that chronic elevation of flow results in arterial luminal enlargement.

Previous studies have shown that elastase aneurysm dimensions can be modified by using specific surgical techniques. For example, the aneurysm neck can be controlled by adjusting the position of the inflated balloon during elastase incubation, ${ }^{20,23}$ and the aneurysm height can be controlled by adjusting the position of the ligation of the RCCA. ${ }^{25}$ Other researchers also reported that the aneurysm height can be controlled by adjusting the position of the sheath in the RCCA. ${ }^{21}$ The current work expands our knowledge regarding optimal methods for elastase-induced aneurysm creation by suggesting that larger aneurysms can be induced following chronic AVF creation.

This study has several limitations. First, a small number of subjects was included. Second, no test of the impact of the aneurysms induced after AVF creation on the frequency of recurrences was performed in the current study. We acknowledge these limitations and are continuing to validate this model.

\section{Conclusions}

Patent carotid-jugular AVFs result in RCCA remodeling that yields relatively large elastase-induced aneurysms.

\section{References}

1. Altes TA, Cloft HJ, Short JG, et al. 1999 ARRS Executive Council Award: creation of saccular aneurysms in the rabbit-a model suitable for testing endovascular devices. AJR Am J Roentgenol 2000;174:349-54

2. Cloft HJ, Altes TA, Marx WF, et al. Endovascular creation of an in vivo bifurcation aneurysm model in rabbits. Radiology 1999;213:223-28

3. Kallmes DF, Fujiwara NH, Yuen D, et al. A collagen-based coil for embolization of saccular aneurysms in a New Zealand white rabbit model. AJNR Am J Neuroradiol 2003;24:591-96

4. Kallmes DF, Williams AD, Cloft HJ, et al. Platinum coil-mediated implantation of growth factor-secreting endovascular tissue grafts: an in vivo study. Radiology 1998;207:519-23

5. De Gast AN, Altes TA, Marx WF, et al. Transforming growth factor betacoated platinum coils for endovascular treatment of aneurysms: an animal study. Neurosurgery 2001;49:690-94

6. AAssar OS, Fujiwara NH, Marx WF, et al. Aneurysm growth, elastinolysis, and attempted doxycycline inhibition of elastase-induced aneurysms in rabbits. $J$ Vasc Interv Radiol 2003;14:1427-32

7. Krings T, Hans FJ, Moller-Hartmann W, et al. Time-of-flight-, phase contrast and contrast-enhanced magnetic resonance angiography for pre-interventional determination of aneurysm size, configuration, and neck morphology in an aneurysm model in rabbits. Neurosci Lett 2002;326:46-50

8. Ding YH, Dai D, Danielson MA, et al. Long-term patency of elastase-induced aneurysm model in rabbits. AJNR Am J Neuroradiol 2006;27:139-41

9. Kadirvel R, Ding YH, Dai D, et al. The influence of hemodynamic forces on biomarkers in the walls of elastase-induced aneurysms in rabbits. Neuroradiology 2007;49:1041-53

10. Dai D, Ding YH, Kallmes DF. Histopathologic and immunohistochemical comparison in human, rabbit, and swine aneurysms embolized with platinum coils. AJNR Am J Neuroradiol 2005;26:2560-68

11. Ding Y, Dai D, Lewis D, et al. Angiographic and histologic analysis of experimental aneurysms embolized with platinum coils, Matrix, and HydroCoil. AJNR Am J Neuroradiol 2005;26:1757-63

12. Kallmes D, Fujiwara N. New expandable hydrogel-platinum coil hybrid device for aneurysm embolization. AJNR Am J Neuroradiol 2002;23:1580-88

13. Dai D, Ding YH, Kallmes DF. Endovascular treatment of experimental aneu- rysms by use of fibroblast-coated platinum coils: angiographic and histopathological study. Stroke 2007;38:170-76

14. Hans FJ, Krings T, Moller-Hartmann W, et al. Endovascular treatment of experimentally induced aneurysms in rabbits using stents: a feasibility study. Neuroradiology 2003;45:430-34

15. Fujiwara NH, Cloft HJ, Marx WF, et al. Serial angiography in an elastaseinduced aneurysm model in rabbits: evidence for progressive aneurysm enlargement after creation. AJNR Am J Neuroradiol 2001;22:698-703

16. Turk AS, Aagaard-Kienitz B, Niemann D, et al. Natural history of the canine vein pouch aneurysm model. AJNR Am J Neuroradiol 2007;28:531-32

17. Kallmes DF, Altes TA, Vincent DA, et al. Experimental side-wall aneurysms: a natural history study. Neuroradiology 1999;41:338-41

18. Fujiwara NH, Kallmes DF. Healing response in elastase-induced rabbit aneurysms after embolization with a new platinum coil system. AJNR Am J Neuroradiol 2002;23:1137-44

19. Raymond J, Darsaut T, Salazkin I, et al. Mechanisms of occlusion and recanalization in canine carotid bifurcation aneurysms embolized with platinum coils: an alternative concept. AJNR Am J Neuroradiol 2008;29:745-52

20. Ding YH, Dai D, Danielson MA, et al. Can aneurysm neck size elastase-induced aneurysms be controlled? A retrospective study. AJNR Am J Neuroradiol 2006;27:1681-84

21. Thiex R, Moller-Hartmann W, Hans FJ, et al. Are the configuration and neck morphology of experimental aneurysms predictable? A technical approach. Neuroradiology 2004;46:571-76

22. Hoh BL, Rabinov JD, Pryor JC, et al. A modified technique for using elastase to create saccular aneurysms in animals that histologically and hemodynamically resemble aneurysms in human. Acta Neurochir (Wien) 2004;146:705-11. Epub 2004 May 17

23. Ding YH, Dai DY, Lewis DA, et al. Can neck size in elastase-induced aneurysms be controlled? A prospective study. AJNR Am J Neuroradiol 2005;26:2364-67

24. Ding YH, Danielson MA, Kadirvel R, et al. Modified technique to create more reproducible elastase-induced aneurysms in rabbits. Neuroradiology 2006;48:528-32

25. Ding YH, Dai D, Lewis DA, et al. Control of aneurysm volume by adjusting the position of ligation during creation of elastase-induced aneurysms: a prospective study. AJNR Am J Neuroradiol 2007;28:857-59

26. Tronc $F$, Wassef $M$, Esposito $B$, et al. Role of NO in flow-induced remodeling of the rabbit common carotid artery. Arterioscler Thromb Vasc Biol 1996;16: $1256-62$

27. Tronc F, Mallat Z, Lehoux S, et al. Role of matrix metalloproteinases in blood flow-induced arterial enlargement: interaction with NO. Arterioscler Thromb Vasc Biol 2000;20:E120-26

28. Castier Y, Brandes RP, Leseche G, et al. p47phox-dependent NADPH oxidase regulates flow-induced vascular remodeling. Circ Res 2005;97:533-40. Epub 2005 Aug 18

29. Ding YH, Dai D, Lewis DA, et al. Intra-venous digital subtraction angiography is an alternative method to intra-arterial digital subtraction angiography for experimental aneurysm imaging. Neuroradiology 2005;47:792-95. Epub 2005 Aug 25

30. Kadirvel R, Ding YH, Dai D, et al. Gene expression profiling of experimental saccular aneurysms using deoxyribonucleic acid microarrays. AJNR Am J Neuroradiol 2008;29:1566-69

31. Kallmes DF, Ding YH, Dai D, et al. A new endoluminal, flow-disrupting device for treatment of saccular aneurysms. Stroke 2007;38:2346-52

32. Dai D, Ding YH, Danielson MA, et al. Endovascular treatment of experimental aneurysms with use of fibroblast transfected with replication-deficient adenovirus containing bone morphogenetic protein-13 gene. AJNR Am J Neuroradiol 2008;29:739-44. Epub 2008 Jan 9

33. Kallmes DF, Ding YH, Dai D, et al. A second-generation, endoluminal, flowdisrupting device for treatment of saccular aneurysms. AJNR Am J Neuroradiol 2009;30:1153-58

34. Killer M, Kallmes DF, McCoy MR, et al. Angiographic and histologic comparison of experimental aneurysms embolized with hydrogel filaments. AJNR Am J Neuroradiol 2009;30:1488-95. Epub 2009 May 27

35. Shin YS, Niimi Y, Yoshino Y, et al. Creation of four experimental aneurysms with different hemodynamics in one dog. AJNR Am J Neuroradiol 2005; 26:1764-67

36. Byrne JV, Hope JK, Hubbard N, et al. The nature of thrombosis induced by platinum and tungsten coils in saccular aneurysms. AJNR Am J Neuroradiol 1997; 18:29-33

37. Raymond J, Salazkin I, Metcalfe A, et al. Lingual artery bifurcation aneurysms for training and evaluation of neurovascular devices. AJNR Am J Neuroradiol 2004;25:1387-90 